\title{
EFFICACY OF DIFFERENT DENTIN POSTS FOR THE TREATMENT OF PRIMARY ANTERIOR TEETH (AN IN VITRO STUDY)
}

\author{
Mennatallah Hesham El-Shaabany ${ }^{1}$, Shaimaa Mohamed Mahfouz Omer $^{2}$, Ghada Abd ElHamid ElBaz ${ }^{3}$
}

DOI: $10.21608 / d s u .2021 .58163 .1059$

Manuscript ID: DSU-2101-1059

\section{KEYWORDS}

Dentin post,

Primary anterior teeth,

Fracture resistance, Push-Out.

- E-mail address: menna.elshaabany@gmail.com

1. Demonstrator at Faculty of Dentistry, Sinai University.

2. Associate Professor of Pediatric and Preventive Dentistry and Dental Public Health, Faculty of Dentistry, Suez Canal University

3. Professor of Pediatric and Preventive Dentistry and Dental Public Health, Faculty of Dentistry, Suez Canal University

\begin{abstract}
Introduction: Early childhood Caries is a distressing situation for patients and parents and pediatric dentists. Aim: current research was carried out to evaluate fracture resistance and bond strength for different types of dentin posts compared to fiber posts. Materials and Methods: This Current in-vitro study was conducted on 48 extracted primary incisors. Samples were split randomly into 4 groups of 12 for each group. Group-I (fiber posts $6 \mathrm{~mm}$ length, $1.4 \mathrm{~mm}$ diameter), Group-II (dentin posts $6 \mathrm{~mm}$ length, 1.4 diameter), Group-III (dentin posts $8 \mathrm{~mm}$ length, $1.4 \mathrm{~mm}$ diameter), Group-IV (dentin posts $8 \mathrm{~mm}$ length, $1.6 \mathrm{~mm}$ diameter). Each group was further subdivided into two subgroups ( 6 for the Push-Out bond strength test and 6 for the fracture resistance test using Universal Testing Machine). Results: It was observed in the fracture resistance test that, Group III showed the highest fracture resistance means (140.678 \pm 11.98$)$ followed by Group IV (131.38 \pm 7.03$)$, Group-II $(94.23 \pm 9.84)$, and finally Group-I that showed the lowest fracture resistance means $(80.465 \pm 2.82)$. Push-Out bond strength test revealed that the highest mean value with Group-IV $(8.653 \pm 1.49)$, followed by Group-II $(6.08 \pm 2.25)$ and Group III $(5.67 \pm 2.44)$ have no statistically significant difference between them, while the lowest mean value was for Group-I. Conclusions: Dentin posts showed increased fracture resistance and bond strength more than fiber posts. The use of dentin post as intra-canal retention in primary anterior teeth possesses the most important advantages over the fiber post. Therefore, biological dentin post is a successful alternative for fiber post.
\end{abstract}

\section{INTRODUCTION}

Crown damage of primary anterior teeth is a frequent issue in pediatrics dental clinics because of either early childhood caries (ECC) or trauma ${ }^{(1)}$. ECC is a quickly progressing developing type of dental caries that occurs primarily in the cervical third of maxillary incisors till full damage of the crown. It principally affects the primary maxillary incisors shortly following the eruption of teeth and infects other primary teeth quickly causing early tooth loss ${ }^{(2)}$.

In primary teeth, gaining intracanal retention through posts is tricky due to that permanent teeth need to find a way for primary counterparts. To ensure well-timed eruption of permanent successors in normal undeflected places, the intracanal post would timely resorb way ${ }^{(3)}$. 
Many types of posts are routinely suggested retention techniques for anterior primary teeth restoration such as metal posts, omega, $\gamma, \alpha$ form of stainless-steel orthodontic wires, polyethylene fiber posts. Nowadays relevant post systems are used e.g. glass fiber, carbon fiber, fiber-reinforced composite, and zirconium oxide posts that provide brilliant characteristics involving corrosion resistance, fatigue, and biocompatibility, in addition to having mechanical features like dentin ${ }^{(4)}$. However, there is no post material demonstrated to be as efficient as natural biological structure especially in the biological and mechanical features ${ }^{(5,6)}$.

Therefore, in this study, we use biological posts and cores are composed of dentinal structure from freshly extracted teeth thus having a similar isotropic structure like that of the tooth to be restored, this similarity enables them to absorb and dissipate stresses ${ }^{(7)}$. Biological posts are compared with each other in their three different dimensions and with fiber posts whose dimensions similar to one of the three groups' dimensions. Fracture resistance and Push-Out bond strength tests were done. There was a difficulty in the collection of primary anterior teeth with two-thirds of the complete roots or complete roots. More studies are needed for studying more physical properties for the biological dentin posts with more different dimensions and comparing them with other types of posts.

The null hypothesis is there is no significant difference in fracture resistance test and push-out bond strength test values between teeth restored with fiber posts and teeth restored with dentin posts with their three different dimensions.

The current research aimed to evaluate and compare: 1-Fracture resistance of primary anterior teeth restored with different dentin posts (length + width) and others restored with fiber posts by using Universal Testing Machine (UTM). 2- Bond strength of dentin posts and fiber posts to root surface by using the Push-Out test.

\section{MATERIALS AND METHODS}

The present study was conducted at the Department of Pediatric Dentistry, Faculty of Dentistry, Suez Canal University, after waived from the approval of the Research Ethical Committee (REC) of the faculty of Dentistry.

Forty-eight extracted upper and lower primary anterior teeth (incisors and canines), were calculated according to $\mathrm{g}^{*}$ power software version 3.1.9.6 with an effect size of 0.50 and power of 0.80 , and partial eta-squared of $0.20^{(8)}$.

\section{Sample grouping of extracted primary anterior teeth:}

Randomization technique was used in grouping during the selection of primary anterior teeth for each group.

Group (I): including (12 anterior teeth) received fiber posts (6mm length and $1.4 \mathrm{~mm}$ diameter).

Group (II): including (12 anterior teeth) received dentin posts $(6 \mathrm{~mm}$ length and $1.4 \mathrm{~mm}$ diameter.

Group (III): including (12 anterior teeth) received dentin posts ( $8 \mathrm{~mm}$ length and $1.4 \mathrm{~mm}$ diameter).

Group (IV): including (12 anterior teeth) received dentin posts ( $8 \mathrm{~mm}$ length and $1.6 \mathrm{~mm}$ diameter).

Primary anterior teeth were gathered from the outpatient clinic of the Pediatric Dentistry Department, Faculty of Dentistry, Suez Canal University. All extracted primary anterior teeth had the following selection criteria:

- Teeth with intact roots (no root caries or root fracture). 
- A minimum of two-thirds of root length still existed.

- No previous pulp therapies were done.

- Teeth were extracted due to orthodontic reasons, traumatic injuries, or retained primary incisors with no or little root resorption.

36 dentine post samples were obtained from 18 maxillary premolars. Selected premolars were obtained from the outpatient dental clinic of the Oral and Maxillofacial Surgery Department, Faculty of Dentistry, Suez Canal University for preparation of dentin posts.

\section{Inclusion Criteria of extracted premolars:}

- $\quad$ Eighteen freshly extracted maxillary premolars with two roots and closed apex.

- Premolars' roots were caries-free.

- They were from patients $\geq 14$ years of age.

- They were extracted for orthodontic reasons.

All collected teeth (primary anterior teeth and premolars) were cleaned with hydrogen peroxide and normal saline to eradicate the residual debris and tissue tags then were stored in a saline solution that was replaced every day at room temperature. ${ }^{(9)}$

\section{Preparation of primary anterior teeth:}

1- Forty-eight extracted primary anterior teeth were cut cross-sectionally perpendicular to the long axis of the tooth $1 \mathrm{~mm}$ above the cementoenamel junction (CEJ) to simulate the badly destructed teeth. $^{(10)}$

2- Root canals were prepared with H-files using copious saline irrigation.

3- Measurement of initial root canal length was made by visual inspection using H-file \#15. ${ }^{(10)}$
4- Canal instrumentation was done to its working length up to the \#45 H-file.

5- After instrumentation and irrigation, the root canal was dried with paper points. Then, the introduction of a thick mix of calcium hydroxide with iodoform paste $\left(\right.$ METAPEX $\left.^{\mathrm{TM}}\right)$ into the root canal ${ }^{(11)}$.

\section{Selection of fiber post:}

In this study, the Hi-Rem prosthetic post brand was selected. We used only the first width (yellow drills and posts) in the posts' pack. Every pack contains three different dimensions of posts with their drills and we used the drill and fiber posts with width $1.4 \mathrm{~mm}$ diameter for group I and the same drill for group II and drill with width $1.6 \mathrm{~mm}$ for group III and IV of dentin posts' groups.

\section{Fabrication of Dentin post:}

Eighteen premolars were cut longitudinally mesiodistally into two halves in a vertical direction to obtain 36 roots for fabrication of 36 dentin posts from sound blocks of dentin out of these 36 halves (Fig 1,2). Sound blocks of dentin were taken out of the roots and were milled by special bur in the Computer Numerical Control milling machine (CNC). Thirty-six dentin posts were divided into three groups according to their different dimensions using a (CNC) milling machine that had the efficacy to control the required dimensions at Abu-Rehab factory for turning and laser cutting, fourth industrial area, 6 October city. ${ }^{(12)}$. It was laboratory work and the researcher could take an idea only about how the dentin posts were constructed.

All the prepared dentin posts were autoclaved at $121 \mathrm{oC}$ for $20 \mathrm{~min}$ to ensure all biosecurity standards for teeth disinfection and to simulate clinical conditions. ${ }^{(4)}$ 


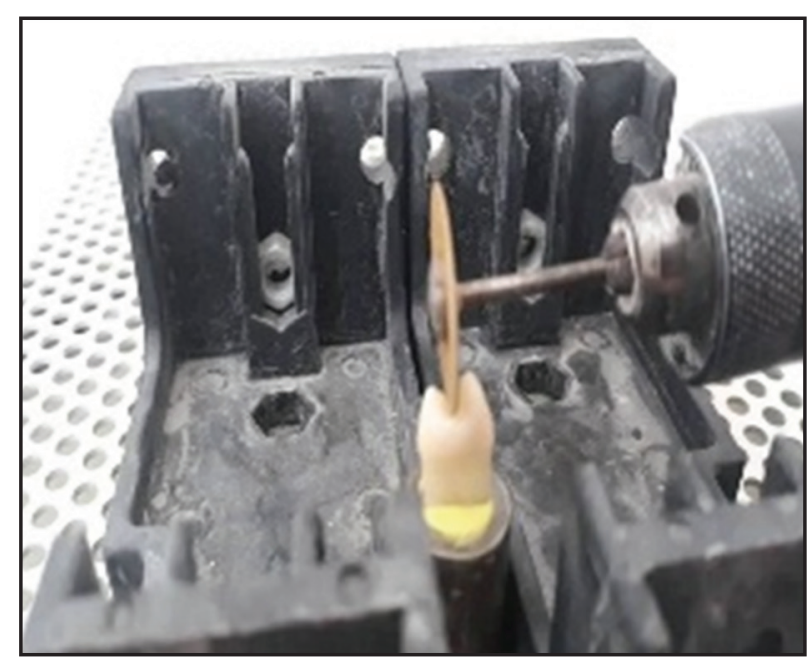

Fig (1) Sectioning premolar mesiodistally in a vertical direction

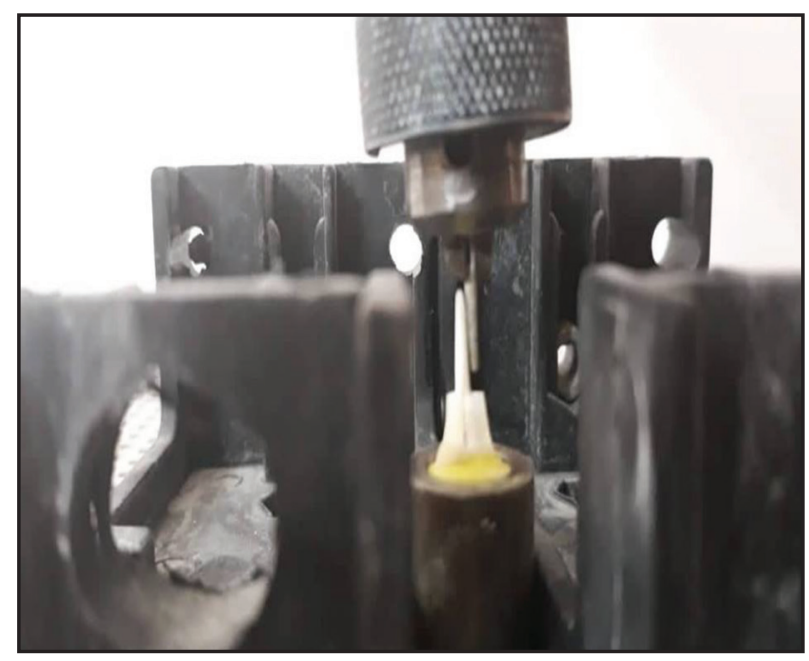

Fig (2) Preparation of dentin post

\section{Preparation of the post space:}

In each group, drilling was done with a drill whose width is corresponding to the posts that were used. The required length was controlled by the drill's stopper to be similar to the dimension of the post used. Posts of each group of the 4 groups were placed in a specific sterilized packet marked with the number of the group.
During condensation of METAPEX into the root canal by a plugger, the plugger was with a stopper that was adjusted at $4 \mathrm{~mm}$ in Groups I and II to ensure that $3 \mathrm{~mm}$ of the canal space free of METAPEX coronally ${ }^{(12)}$, and was adjusted at $6 \mathrm{~mm}$ in groups III and IV to ensure that $5 \mathrm{~mm}$ of the canal space free of METAPEX coronally.

\section{Post-placement, cementation, and core build-up:}

All these posts were placed into prepared intracanal spaces according to the different treatment modalities of each group.

Following the satisfactory adaptation of the posts in the 4 groups (48 specimens), clinically, the post shouldn't be loosed with marked space between the post and the dentin canal wall, and digital radiographic assessments were done. (Fig 3)

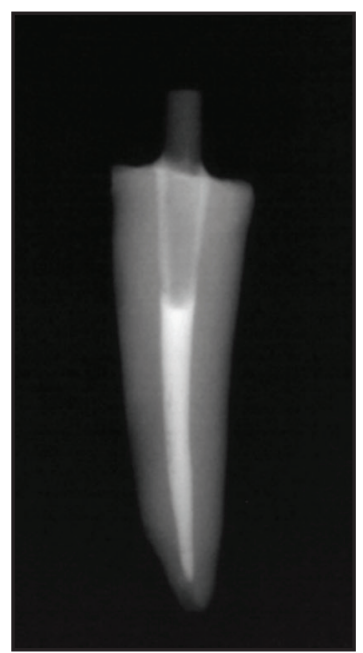

Fig (3) Digital radiograph after cementation

The posts were cemented in the root canals with a dual-curing, self-adhesive resin luting cement, (RelyX ${ }^{\mathrm{TM}}$ Unicem). Finally, after cementation, digital radiographs were taken. In half of the prepared teeth of each group (6 samples for each 
group) (24 total teeth), restoration of the crowns was built up with Filtek ${ }^{\mathrm{TM}}$ Supreme XT Lightactivated composite restorative material ${ }^{(10)}$. Layer by layer technique was used for core buildup, each increment was $1-2 \mathrm{~mm}$ until finishing the core with standardized dimensions $\left(4 \mathrm{~mm}^{*} 4 \mathrm{~mm} * 3 \mathrm{~mm}\right)$ for all the samples that needed core build up in the study ${ }^{(13)}$

\section{Thermocycling:}

Samples were thermocycled for 5000 cycles between $5^{\circ} \mathrm{C}$ to $55^{\circ} \mathrm{C}$ with a dwell time of 30 seconds at each temperature ${ }^{(14)}$. This procedure took about 3 days for finishing the cycles in the laboratory of the fixed prosthodontics department, faculty of Dentistry, Sinai University.

\section{Evaluation of fracture resistance:}

1. Twenty-four roots restored by composite resin core build-up were used to evaluate the fracture resistance by the Universal Testing Machine (UTM).

2. They were mounted in circular self-cured dental supply acrylic resin blocks $(D=15 \mathrm{~mm}$, $\mathrm{L}=15 \mathrm{~mm}$ ).

3. A typical clinical model with a facio-lingual tooth inclination of $45^{\circ}$ angle was chosen for the fabrication of the fracture resistance test secured to the lower fixed compartment of a computerized controlled materials testing machine..$^{(12)}$

4. Failure loads were measured under a static loading test using the machine with a loadcell of $5 \mathrm{KN}$ (K Newton).

\section{Evaluation of bond strength:}

1. Twenty-four roots that were left without core built up, were used to assess the Push-Out bond strength of the different posts applied during the study by Universal Testing Machine (UTM) and mounted in circular self-cured acrylic blocks $(\mathrm{D}=10 \mathrm{~mm}, \mathrm{~L}=15 \mathrm{~mm})^{(12)}$.

2. Each sample was sectioned transversely and perpendicular to the root long axis by a watercooled precision saw to utilize a section thickness of $2.0 \pm 0.1 \mathrm{~mm}$ from the roots' coronal thirds.

3. Every root-slice was affixed in a customized loading fixture [metallic block with a central circular cavity for specimen housing with a central hole to enable displacement of extruded filling material], then exposed to compressive loading at a crosshead speed of $1 \mathrm{~mm} / \mathrm{min}$ via computer-controlled materials testing machine.

\section{Statistical analysis}

Data was calculated, tabulated, and statistically analyzed using SPSS version 23.0 for Mac OS. Differences were evaluated by one-way ANOVA and Duncan's Multiple Range Test (DMRTs) used as a post hoc at P-value 0.05 .

\section{RESULTS}

The results of this study were divided into two main parts:

I. Fracture resistance results.

II. Push-Out bond strength results.

\section{I) Fracture resistance test results:}

There was a statistical significance $(p<0.001)$ difference in the mean fracture resistance between the four groups, as revealed by one-way ANOVA, with the highest mean fracture resistance of group 
III (with dentin posts $8 \mathrm{~mm}$ length, $1.4 \mathrm{~mm}$ diameter) and the lowest mean fracture resistance of group I (with fiber posts $6 \mathrm{~mm}$ length, $1.4 \mathrm{~mm}$ diameter) (Table 1). according to DMRTs, means followed by different superscripts are significantly different at $p<0.05$

Table (1) comparison between the four treatment groups in fracture resistance test:

\begin{tabular}{|l|c|c|c|}
\hline \multirow{2}{*}{$\begin{array}{c}\text { Groups } \\
(\mathrm{n}=4)\end{array}$} & $\begin{array}{c}\text { Mean } \pm \mathrm{SD} \\
(\mathrm{n}=12)\end{array}$ & \multicolumn{2}{|c|}{ One-way ANOVA } \\
& F- ratio & $p$-value \\
\hline Group-I & $80.47^{\mathrm{d}} \pm 2.82$ & & \\
\cline { 1 - 2 } Group-II & $94.23^{\mathrm{c}} \pm 9.84$ & \multirow{1}{*}{112.47} & $<0.001 * *$ \\
\hline Group-III & $140.68^{\mathrm{a}} \pm 11.98$ & & \\
\cline { 1 - 2 } Group-IV & $131.38^{\mathrm{b}} \pm 7.03$ & & \\
\hline
\end{tabular}

**, significant at $p$-value $(p<0.5)$ using one-way ANOVA
(a) The highest value.
(b) The second high value
(c) The third high value
(d) The lowest value

\section{II) Push-Out bond strength test results:}

According to statistical analysis comparison between all treatment groups, results showed that there was a statistical significant difference $(p<0.01)$ in the mean of Push-Out bond strength with the highest mean bond strength of group IV (with dentin posts $8 \mathrm{~mm}$ length, $1.6 \mathrm{~mm}$ diameter) and the lowest mean bond strength of group I (with fiber posts $6 \mathrm{~mm}$ length, $1.4 \mathrm{~mm}$ diameter) but the difference between groups II and III was statistically non-significant $(p<0.05)$ (Table 2, Fig 5).
Table (2) comparison between the four treatment groups for Push-Out bond strength test

\begin{tabular}{|c|c|c|c|}
\hline Groups & $\begin{array}{c}\text { Push out Bond } \\
\text { Strength (Mpa) } \\
\quad(\mathrm{n}=12)\end{array}$ & F-ratio & $p$-value \\
\hline & Mean \pm SD & \multirow{5}{*}{29.41} & \multirow{5}{*}{$0.0013 * *$} \\
\hline Group-I & $3.10^{c} \pm 1.64$ & & \\
\hline Group-II & $6.08^{b} \pm 2.25$ & & \\
\hline Group-III & $5.67^{b} \pm 2.44$ & & \\
\hline Group-IV & $8.65^{\mathrm{a}} \pm 1.49$ & & \\
\hline
\end{tabular}

**, significant at $P$ - value $(p<0.5)$ using one-way ANOVA

(a) The highest value.

(b) The second high value

(c) The third high value

(d) The lowest value

\section{DISCUSSION}

In the current study forty-eight, upper and lower primary incisors and canines were used as in agreement with Ghazawy and Badran, ${ }^{(12),}$ who used primary incisors in their study due to their large root diameter in comparison to roots of primary molars, the ease of canal preparation for primary incisors' canal anatomy and there is limited availability for finding extracted primary molars with complete roots.

Using posts in the restoration of severely mutilated primary anterior teeth is complex than that in permanent ones as it may interfere with normal exfoliation of the primary teeth. In this study, dentin posts were chosen to avoid interference with the normal shedding activity and prevent the eruption of permanent teeth in abnormal deflected positions ${ }^{(3)}$. 
No material has proper properties as the root dentin like dentin itself. Physio-mechanical features of dentin posts are similar to root dentin that lead to even stress distribution. Furthermore, root canal internal dentin walls were preserved with biocompatibility and adapt to conduct configuration ${ }^{(15)}$.

In this current study upper premolars were used for dentine posts' fabrication because they are the common teeth that were extracted for orthodontic reasons, and ease of finding them in their sound form $^{(16)}$.

In this study forty-eight, primary anterior teeth were cut cross-sectionally perpendicular to teeth long-axis leaving $1 \mathrm{~mm}$ of coronal structure with a diamond fissure bur to simulate the badly destructed teeth $^{(12,17)}$.

METAPEX $^{\mathrm{TM}}$ is used as an obturating material after pulp therapy for the primary anterior teeth to provide an antibacterial property that can disinfect the root canal without any teeth discoloration instead of using Zinc oxide eugenol (ZOE) ${ }^{(12,18)}$. Zinc oxide eugenol inhibits the polymerization process of resin composites by phenolic compound of eugenol.

The RelyX cement does not need the step of root dentin surface treatment (etching and bonding) before cementation; That was agreed with Marchan et al. ${ }^{(19)}$ who found that fiber posts have high bond strength when bonded with self-adhesive resin cement. Moreover, Watzke et al ${ }^{(20)}$ found that for the fiber-reinforced posts cemented with selfadhesive, greater pull-off was observed than one cemented with conventional adhesive techniques requiring etching and bonding before cementation with radicular dentin.

Satisfactory adaptation for the posts of the 4 groups should be assessed by digital radiography to determine the accurate apical approach of the posts, ensure that there were not any remnants of
METAPEX $^{\mathrm{TM}}$ on the dentinal wall to ensure that there are not any spaces between the METAPEX ${ }^{\mathrm{TM}}$ and the post ${ }^{(10)}$.

In the current study, layering protocol is used in the composite resin core build-up, each increment is 1-2 $\mathrm{mm}$ to reduce the polymerization shrinkage of the composite resin ${ }^{(13)}$.

All samples were thermocycled in this study using 5000 cycles at $5^{\circ}$ and $55^{\circ}$ for simulating oral environment (every 10000 cycles equivalent 1 year intraorally) ${ }^{(4,17)}$, so these cycles equivalent 6 months intraorally.

Fracture resistance is considered one of the most important and desirable features of restoration materials. In this test, the loading angle which was applied on specimens was $135^{\circ}$ that was preferred to enhance a contact angle in class-I occlusion between maxillary and mandibular anterior teeth ${ }^{(21)}$.

In this current study, results proved that fracture resistance of teeth restored with dentin posts was greater than that restored with fiber posts. This agrees with Kathuria et al ${ }^{(22)}$ who reported that dentin restored teeth showed higher fracture resistance than those restored with fiber posts based on some factors as physio-mechanical features of dentin post, uniform stress distribution, and shockabsorbing potential of dentin post.

The Push-Out bond strength test possesses a good approximation of the bond strength than the conventional shear test. Push-Out fracture develops corresponding to dentin-bonding interface ${ }^{(23,24)}$, which makes it a true shear test and simulates the clinical condition more closely. Group IV with the largest diameter showed the highest Push-Out bond strength value, which may mean that decreasing the cement space between the post and root dentin wall increases the Push-Out bond strength. Ghazawy and Badran, ${ }^{(12)}$ concluded that biological and composite 
posts showed significantly higher Push-Out bond strength value versus fiber posts. They resulted that the lower bond strength of the fiber post group may be attributed to that, the polymer matrix of the commercial fiber-reinforced composite posts is highly cross-linked, which decreases the effect of the adhesive luting agent's active monomers to allow the chemical bonds ${ }^{(25)}$.

Farid et al ${ }^{(26)}$ stated that an increase in cement thickness when the canal diameter is markedly larger than the post diameter would decrease bond strength of fiber posts to root dentin after using selfadhesive cement; but, the self-etch adhesives were not affected.

There is a deficiency of evidence in the literature concerning the use of biological (dentin) posts in primary teeth. It has been suggested that posts' lengths in permanent teeth must be at least equal to the crown height or two-thirds of the root length to facilitate stress distribution and resist occlusal forces. There is no evidence of using long posts in primary teeth due to the physiological resorption that primary teeth undergo. None of the previous studies also compared the effect of the length and width of dentin posts. Furthermore, Bond Strength was neither examined.

There were some limitations in the current study; The difficulty of primary anterior teeth collection that was with complete roots or at least two-thirds of the roots were intact, the difference in diameters between primary incisors' roots may slightly affect the fairness of results, preparation of fortyeight teeth canals for achieving uniform diameters was time-consuming, any resin cement has low solubility and resorpability that are considered impediments for the resorption process during the exfoliation of primary teeth when applied in Vivo studies, dehydration of specimens may consider a problem during the root canal preparation till post cementation in comparison to Vivo studies in which teeth are always in the hydrated field, the practical steps of this study were time and cost consuming.

\section{CONCLUSIONS}

1. The biological dentin post is a successful alternative for fiber post as the fracture resistance results for both are comparable plus the unique advantage of normally resorbed dentin post as a part of the tooth during exfoliation time.

2. The dentin posts with their different dimensions showed higher Push- Out bond strength than that of fiber posts which may contribute in clinical success in other future Vivo studies.

3. Dentin posts with the highest length and width showed the highest Push-Out bond strength value but increasing this width decreased the fracture resistance value of the tooth. More studies are needed for more different dimensions of dentin post and more tests for accurately determining the dentin post's dimension that shows the best results.

\section{REFERENCES}

1. Ferreira M, Kummer T, Vieira R, Calvo M. Short resinposts bonding to primary dentin. Microleakage and micromorphological in vitro study. J Clin Pediatr Dent. 2007; 31: 202-206.

2. Rajesh R, Baroudi K, Reddy K, Praveen B, Kumar V, Amit S. Modified Anchor Shaped Post Core Design for Primary Anterior Teeth. Hindawi Publishing Corporation. Case Rep Dent 2014; 2014: 306910.

3. Mittal N, Bhatia H, Haider K. Methods of intracanal reinforcement in primary anterior teeth- Assessing the outcomes through a systematic literature review. Int J of Clinical Pediatr Dent. 2015; 8: 48-54.

4. Seraj B, Ghadimi S, Estaki Z, Fatemi M. Fracture resistance of three different posts in restoration of severely 
damaged primary anterior teeth: An in vitro study. Dent Res J. 2015; 12: 372-378.

5. Galindo V, Nogueira J, Yamasaki E, Miranda D. Biological posts and natural crowns bonding-alternatives for anterior primary teeth restoration. J Bras Odontoped Odontol Bebe. 2000; 16: 513-520.

6. Andreason J, Ravn J. Epidemiology of traumatic dental injuries to primary and permanent teeth in a Danish population sample. Int J Oral Surg. 1972; 1: 235-239.

7. Andreason F, Norẽn J, Andreason J, Engelhardtsen S, Lindh-Strỏmerg U. Long-term survival of fragment bonding in the treatment of fractured crowns: A multicenter clinical study. Quin Int. 1995; 26: 669-681.

8. Faul, F, Erdfelder, E. Lang AG \& Buchner A. G*Power 3: A flexible statistical power analysis progrm for the social, behavioral, and biomedical sciences. Behav Res Meth. 2007;39, 175-191.

9. Reena R, Gill S, Miglani A. Storage media: A neglected variable for in vitro studies. J of Ind Ortho Soc. 2011; 45: $5-8$.

10. Fawzy A, Farag MS., Saniour SH. Evaluation and comparison of composite posts and glass fiber posts in restoring badly decayed primary incisors: In vivo study. EDJ. 2014; 60: 1725-1735.

11. Jain J, Shukla S, Singh K. Biological Post: AReconstructive Approach to Achieve Aesthetics. Br J. Med Med Res. 2015; 9: 1-5.

12. Ghazawy R, Badran A. Comparative evaluation of fracture resistance of primary anterior teeth restored with long dentin posts and teeth restored with short fiber posts: An in vitro study, Future Dent J. 2018; 4: 54-58.

13. Grewal N, Seth R. Comparative in vivo evaluation of restoring severely mutilated primary anterior teeth with biological post and crown preparation and reinforced composite restoration. J Indian Soc Pedod Prevent Dent. 2008; 8: 141-148.

14. Ernst C, Canbek K, Euler T, Willershausen B. in vivo validation of the historical in vitro thermocycling temperature range of dental materilas testing. Clin Oral Investig. 2004; 8: 130-138.

15. Yogesh B, Srinivas M, Sreedevi P, Shetty C, Kumar A, Ashwini. Dentin post: A challenging post for commer- cially available posts. Int J of Adv Res. 2016: 4: 326-330.

16. Palekar A, Mantri V, Kamble S, Ali S, Magar S. A comparative evaluation of the fracture resistance of teeth restored with glass fiber post and biological dentin post cemented with adhesive resin: An in-vitro study. Ind J of Dent. Sci. 2014; 5: 2231-2293.

17. Correa-Faria P, De alcantara C, Caldas-Diniz M, Bptelho A, Tanavo K. "Biological restoration" root canal and coronal reconstruction. J Compilation Wiley-Periodicals. 2010; 22: 168-177.

18. Schwartz R, Robbins J. Post placement and restoration of endodontically treated teeth: A literature review. J Endod. 2004; 30: 289-301.

19. Marchan S, Coldero L, Whiting R, Barclay S. In vitro evaluation of the retention of zirconia-based ceramic posts luted with glass ionomer and resin cements. Braz Dent J. 2005; 16: 213-217.

20. Watzke R, Blunck U, Frankenberger R, Naumann M. Interface homogeneity of adhesively luted glass fiber posts. Dent Mat In Press. 2008; 24: 1512-1517.

21. Cuzy G, Nicholis J. In vitro comparison of intact endodontically treated teeth with and without endo-post reinforcement. J Prosthest Dent. 1979; 42: 39-44.

22. Kathuria A, Kavitha M, Khetarpal S. Ex vivo fracture resistance of endodontically treated maxillary central incisors restored with fiber-reinforced composite posts and experimental dentin posts. Jur. of Cons. Dent. 2011; 14: 401-405.

23. Ranjithkumar S, Velmurugan N, Roy A, Hemamalathi S. Comparative evaluation of the regional micro-push-out bond strength of custom-made resin post system with a prefabricated resin post: an in vitro study. Ind J Dent Res. 2012; 23: 484-494.

24. Sudsangiam S, Van Noort R. Do dentin bond strength tests serve a useful purpose? J Adhes Dent. 1999; 1: 57-67.

25. Nova V, Karygianni L, Altenburger M, Wolkewtiz M, Kielbassa A, Wrbas K. Pull-Out bond strength of a fibrereinforced composite post system luted with self-adhesive resin cements. J Dent. 2013; 41: 1020-1026.

26. Farid F, Rostami K, Habibzadeh S, Kharazifard M. Effect of cement type and thickness on push-out bond strength of fiber posts. J Dent Res Dent Clin Dent Prospect. 2018; 12: $277-282$. 